ORDINES MILITARES

COLLOQUIA TORUNENSIA HISTORICA

Yearbook for the Study of the Military Orders

ISSN (print) 0867-2008 / ISSN (online) 2391-7512

DOI: http://dx.doi.org/10.12775/OM.2016.007

pp. $129-154$

Kristjan Toomaspoeg

Dipartimento dei Beni delle Arti e della Storia

Università degli Studi di Lecce

Viale Gallipoli 49

I-73100 Lecce

Italy

k_toomaspoeg@hotmail.com

\title{
DER VERLUST DER BESITZUNGEN DES DEUTSCHEN ORDENS IN ITALIEN AM ENDE DES 15. UND ZU BEGINN DES 16. JAHRHUNDERTS
}

\section{KEYWORDS}

Military Orders; Teutonic Order; Reformation; Benefice; Papal Court; Italian Peninsula

I

m I 5. Jahrhundert besaß der Deutsche Orden auf der italienischen Halbinsel vier Balleien, Sizilien, Apulien, 'Lamparten' (Lombardei) und Südtirol ('An der Etsch und im Gebirge'), die mit umfangreichem Grundbesitz, Gutshöfen, landwirtschaftlichen Flächen, Kirchen und Häusern ausgestattet waren und jährlich mehrere tausend Goldflorinen einbrachten. ${ }^{.}$Ähnlich wie der Johanniterorden verwaltete der Deutsche Orden seine italienischen Besitzungen mit geringem Personal, so dass die Zahl der Ordensbrüder sehr niedrig blieb. ${ }^{2}$ Dennoch spielte der Orden in der italienischen Gesellschaft eine nicht unwichtige Rolle und war in

${ }^{1}$ Vgl. dazu K. Forstreuter, Der Deutsche Orden am Mittelmeer (Quellen und Studien zur Geschichte des Deutschen Ordens 2), Bonn 1967; und Der Deutsche Orden zwischen Mittelmeerraum und Baltikum. Begegnungen und Konfrontationen zwischen Religionen, Völkern und Kulturen (Acta Theutonica 5), hrsg. v. H. Houben, K. Toomaspoeg, Galatina 2008. Zur Ballei An der Etsch siehe Der Deutsche Orden in Tirol. Die Ballei an der Etsch und im Gebirge (Quellen und Studien zur Geschichte des Deutschen Ordens 43), hrsg. v. H. Noflatscher, Marburg 1991.

${ }^{2}$ H. Houben, Die Landkomture der Deutschordensballei Apulien (1225-1474), Sacra Militia. Rivista di storia degli ordini militari 2 (2001), S. 116-154; K. Toomaspoeg, Die Brüder des

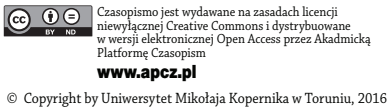


Städten wie Padua, Venedig, Bologna, Barletta und Palermo sehr angesehen. ${ }^{3}$ Erst ab dem letzten Viertel des I 5. Jahrhunderts verlor der Orden in kurzer Zeit fast alle seine italienischen Besitzungen. Dies geschah ungefähr zwischen dem zweiten Thorner Frieden I 466 und der protestantischen Reform, die die Umwandlung des preußischen Ordenstaats in ein weltliches Herzogtum bewirkte.

Das Ende der italienischen Balleien des Deutschen Ordens fand in der deutschen Forschung durch die Studien von Karl Schellhass, ${ }^{4}$ Bruno Schumacher, ${ }^{5}$ Kurt Forstreuter ${ }^{6}$ und Johann Rainer ${ }^{7}$ erhebliche Aufmerksamkeit. Für diese Historiker bestand ein enger Zusammenhang zwischen dem Verlust dieser Balleien und dem Rückzug des Ordens aus dem Mittelmeerraum, also dem Heiligen Land, Kleinarmenien, Zypern, Griechenland und Südfrankreich. Dabei hätte auch die Schwächung des Ordens und seines Hochmeisters nach der Niederlage von Tannenberg ( I 4 I O) eine Rolle gespielt. Es muss jedoch außerdem berücksichtigt werden, dass der Verlust der einzelnen Ordensbesitzungen auch im Zusammenhang des historischen Kontexts Italiens und verschiedener lokaler Entwicklungen gesehen werden muss.

In der zweiten Hälfte des I 5. Jahrhunderts wurden Apulien und Sizilien von den Folgen des großen abendländischen Schismas (1378-1417) erschüttert. Die Sizilianer, die damals drei Päpsten gleichzeitig gehorcht hatten, wurden aufgrund des in ihrer korrupten Kirche verbreiteten moralischen Niedergangs als "Schüler des Verderbens” bezeichnet. ${ }^{8}$ Auf der süditalienischen Halbinsel klagte man dar-

Deutschen Ordens in Italien, Ordines Militares. Yearbook for the Study of the Military Orders 19 (2014), S. 87-113.

3 K. Toomaspoeg, "Confratres, procuratores, negociorum gestores et factores eorum..." Storia dei familiares dei Cavalieri Teutonici in Sicilia (1197-1492), Sacra Militia. Rivista di storia degli ordini militari 1 (2000), S. 151-165; ders., The Teutonic Order in Italy: An Example of the Diplomatic Ability of the Military Orders, in: The Military Orders, Vol. 5: Politics and Power, ed. P. W. Edbury, Burlington-Farnham 2012, S. 273-282. Auch Heinrich Hoemeister, Stathalter der Ballei Sizilien, behauptet in seinem hier im Anhang editierten Brief, dass der Deutsche Orden auf der Insel maxime ponderis et reputacionis sei.

4 K. Schellhass, Die Deutschordenskommende zu Padua und die Jesuiten. Ein Beitrag zur Geschichte des Deutschordens in den Jahren 1511-1575, Quellen und Forschungen aus italienischen Archiven und Bibliotheken 7 (1904), S. 91-120.

5 B. Schumacher, Studien zur Geschichte der Deutschordensballeien Apulien und Sizilien, AltpreuBische Forschungen 18 (1941), S. 187-230 (I); 19 (1942), S. 1-25 (II).

6 Forstreuter, Der Deutsche Orden (wie Anm. 1).

7 J. Rainer, Zur Geschichte des DO priorates SS. Trinità in Venedig vornemlich im 16. Jahrhundert, in: Acht Jabrhunderte Deutscher Orden in Einzeldarstellungen (Quellen und Studien zur Geschichte des Deutschen Ordens 1), hrsg. v. K. Wieser, Bad Godesberg 1967, S. 357-370.

8 S. Fodale, Alunni della perdizione. Chiesa e potere in Sicilia durante il grande scisma (1372-1416) (Nuovi studi storici 80), Rom 2008, S. 745-772, mit mehreren eloquenten Beispielen. 
über, dass einige Klöster sich in Tavernen und Bordelle verwandelt hatten. ${ }^{9}$ Der Klerus hielt sich häufig Konkubinen und junge Nonnen führten inner- und außerhalb der Klostermauern ein 'fröhliches Leben', Besitz und Einnahmen der Kirchen wurden zu privaten Zwecken benutzt.

Hinzu kam, dass seit der Mitte des I 5 . Jahrhunderts in Süditalien die Zentralgewalt wieder stärker wurde und die Herrschaft über den Kirchenbesitz allgemein beanspruchte und besonders über die Ritterorden. ${ }^{10}$ In der Ballei Sizilien, deren Landkomtur ein Vassall des Königs war, war der Einfluss des Königshofs bereits seit dem Ende des I 4. Jahrhunderts sehr stark; dort wurde der Ordensbesitz bereits in den dreißiger Jahren des I 5 . Jahrhunderts zeitweilig direkt von Hof verwaltet. ${ }^{11}$ Ein Jahrzehnt später wurde das Königreich Neapel (Sicilia citerior), in dem die Ballei Apulien lag, von Alfons dem Großmütigen, König von Aragon und Sizilien, erobert, so dass auch hier die Lage immer problematischer wurde. Dies betraf nicht nur die Besitzungen des Deutschen Ordens, sondern auch die der Johanniter, deren Priorate in die Hände königlicher Getreuer gelangten, wie z. B. das Priorat von Capua, das Pirro Caracciolo übergeben wurde. ${ }^{12}$ Weiter nördlich, in Mittelitalien, wurden die Besitzungen des Deutschen Ordens von der Expansion und Verstärkung des Kirchenstaats bedroht, ähnlich wie in Norditalien durch die neuen Regionalstaaten Mailand und besonders Venedig.

Verstärkt wurden diese Probleme durch Zögern, Zweifel und Intrigen der zentralen Verwaltung des Deutschen Ordens im Laufe des I 5 . Jahrhunderts, wel-

9 P. Dalena, Dagli Itinera ai percorsi. Viaggiare nel Mezzogiorno medievale, Bari 2003, S. 166.

10 Siehe C. de Ayala Martínez, Las Órdenes militares y los procesos de afirmación monárquica en Castilla y Portugal (1250-1350), Revista da Faculdade de Letras-Historia 15 (1998), 2, S. 1279-1312; P. Josserand, Église et pouvoir dans la Péninsule Ibérique. Les ordres militaires dans le royaume de Castille (1252-1369) (Bibliothèque de la Casa de Velázquez 31), Madrid 2004, S. 463-647. Für Sizilien: K. Toomaspoeg, Templari e Ospitalieri nella Sicilia Medievale (Gran Priorato di Napoli e Sicilia del Sovrano Militare Ordine di Malta, Melitensia 11), Bari 2003, S. 88-101. Der Jurist Giovanni Luca Barberi hat am Anfang des 16. Jh. behauptet dass der Hauptteil des sizilianischen Kirchenbesitzes dem König gehörte: F. Nobile, I Codici di Giovan Luca Barberi sullo stato delle regalie della monarchia Siciliana nei primordi del decimosesto secolo, studio biografico-critico, Palermo 1892.

11 S. Fodale, Antonio Olzina: un cavaliere di Santiago precettore dei teutonici nella Sicilia alfonsina, in: Territorio, culture e poteri nel Medioevo e oltre. Scritti in onore di Benedetto Vetere (Università del Salento. Dipartimento dei Beni delle Arti e della Storia. Saggi e testi 46), hrsg. v. C. Massaro, L. Petracca, vol. 1, Galatina 2011, S. 277-282.

12 Il "Codice Chigi". Un registro della cancelleria di Alfonso I d'Aragona re di Napoli per gli anni 1451-1453 (Università degli studi di Napoli, Istituto di paleografia e diplomatica 5), hrsg. v. J. Mazzoleni, Neapel 1965, Nr. 55, S. 56-57. 
che die süditalienischen Balleien schwächten. ${ }^{13}$ Die Balleien Apulien und Sizilien wurden in der Tat zum Spielball der Machtkämpfe zwischen den Deutschmeistern und den Hochmeistern. Letztere versuchten, diese beiden Balleien, die bis dahin vom Deutschmeister verwaltet wurden, dem Sitz des Generalprokurators des Deutschen Ordens an der römischen Kurie zu unterstellen, was ihnen dann zwischen 1456 und 1466 auch gelang. ${ }^{14}$

Der Beginn des Verlusts der süditalienischen Ordensbesitzungen fand im Jahre I 469 statt, als Dietrich Hochgesang von Kaub (oder de Cuba) Generalprokurator wurde. ${ }^{15}$ Seine Ernennung war das Ergebnis eines Kompromisses zwischen Hochmeister und Deutschmeister. Kaub, ein gebürtiger Frankfurter, der in Padua zum doctor iuris canonici promoviert worden war, war ein Getreuer des Deutschmeisters. Seit ca. I 470 wurde ihm auch die Verwaltung der Ballei Apulien übertragen, wodurch diese Ballei praktisch sowohl dem Deutschmeister als auch dem Hochmeister unterstellt wurde, da Kaub als Landkomtur dem Deutschmeister und als Generalprokurator dem Hochmeister unterstand. Noch bevor Kaub, nachdem er zum Bischof von Samland ernannt worden war, I 473 Rom verließ, um sich in sein Bistum nach Preußen zu begeben, unterstellte er I 47 I die Ballei Sizilien wieder dem Deutschmeister, dessen Statthalter Heinrich Hoemeister hier seit August I $47 \mathrm{I}$ bezeugt ist. ${ }^{16} \mathrm{Um}$ I 473 , oder vielleicht kurz vorher, wurde auch Apulien dem Deutschmeister Ulrich von Lentersheim zurückgegeben. ${ }^{17}$ Dieser ernannte zum neuen Landkomtur seinen Getreuen Vinzenz von Leubint, ${ }^{18}$ der gleichzeitig auch Landkomtur von Lamparten und Griechenland (Romania) blieb. Da es in Sizilien schon seit I 456 keinen Landkomtur, sondern nur noch einen Statthalter gab,

13 Siehe J. Vincke, Nachrichten über den Deutschen Orden in Spanien, Gesammelte Aufsätze zur Kulturgeschichte Spaniens 13 (1958), 3, S. 263-270.

14 K. Toomaspoeg, Les Teutoniques en Sicile (1197-1492) (Collection de l'École française de Rome 321), Rom 2003, S. 296-297.

15 H. Freytag, Die Geschäftsträger des Deutschen Ordens an der Römischen Kurie von 1309 bis 1525, Zeitschrift des Westpreußischen Geschichtsvereins 49 (1907), S. 185-220, hier S. 210; K. Forstreuter, Cuba, Dietrich von, Neue Deutsche Biographie 3 (1957), S. 435; ders., Der Deutsche Orden (wie Anm. 1), S. 175; J.-E. Beuttel, Der Generalprokurator des Deutschen Ordens an der römische Kurie. Amt, Funktionen, personelles Umfeld und Finanzierung (Quellen und Studien zur Geschichte des Deutschen Ordens 55), Marburg 1999, S. 66 f.; Houben, Die Landkomture (wie Anm. 2), S. 152.

161471 August 25.: A. Mongitore, Monumenta historica sacrae domus mansionis SS. Trinitatis militaris ordinis Theutonicorum urbis Panormi et magni ejus praeceptoris, Palermo 1721, S. 162. K. Toomaspoeg, Ultimi Teutonici di Sicilia (1491-1492), Sacra Militia. Rivista di storia degli ordini militari 2 (2001), S. 155-177, hier S. 163.

17 Dazu Schumacher, Studien (wie Anm. 5), I, S. 221-230; und Forstreuter, Der Deutsche Orden (wie Anm. 1), S. 131.

18 Houben, Die Landkomture (wie Anm. 2), S. 152, Anm. 233. 
wurde Leubint praktisch nun zum höchsten Beamten des Deutschmeistertums in ganz Italien.

Die Machtverhältnisse zwischen Deutschmeister, Hochmeister und Generalprokurator waren so unklar, dass einzelne Personen durch Intrigen die Ordensbesitzungen zur Verwirklichung persönlicher Interessen und Ambitionen benutzen konnten. Im März I 473 ist als Statthalter des Generalprokurators in Apulien $^{19}$ der aus Leipzig gebürtige Stephan Grube ${ }^{20}$ bezeugt, welcher I 46 I in Bologna sein Universitätsstudium abgeschlossen hatte und daher Italien gut kannte. Er residierte im Haupthaus der Ballei in San Leonardo di Siponto und verwehrte dem neuen Landkomtur Vinzenz von Leubint den Zugang nach Apulien. ${ }^{21}$ Nun kam eine neue Kraft ins Spiel: die römische Kurie. Am Hof Sixtus' IV. konnte man mit guten Beziehungen und viel Geld so gut wie alles erreichen. Die Stellung des Deutschen Ordens war nicht stark genug, um einem geschickten Diplomaten wie Grube zu widerstehen, der auch über die umfangreichen Geldressourcen der Ballei verfügte. ${ }^{22}$ Am ı o. März I 474 übergab Grube die Ballei dem Papst und erhielt von diesem dafür das Bischofsamt von Troia in Apulien und das Recht die Einkünfte der Ballei weiter einzunehmen, so lange er lebte. ${ }^{23}$

Es folgten intensive diplomatische Verhandlungen, die im sogenannten Ordensbriefarchiv, das heute im Geheimen Staatsarchiv Preußischer Kulturbesitz in Berlin aufbewahrt wird, gut dokumentiert sind. Zunächst kontaktierte Grube die deutschmeisterliche Verwaltung, um sich als Verteidiger des Ordensbesitzes darzustellen. ${ }^{24}$ Dann reichte Vinzenz Leubint im April I 474 durch seinen Prokurator Giovanni Bacta di Bentivoglio bei König Ferdinand I. in Neapel ein Protestschreiben gegen die Usurpation der Ballei ein, während Stephan Grube

191473 März 8.: Regesto di S. Leonardo di Siponto (Regesta Chartarum Italiae 10), hrsg. v. F. Camobreco, Rom 1913, Nr. 337, S. 268.

20 Freytag, Die Geschäftsträger (wie Anm. 15), S. 212-213; Forstreuter, Der Deutsche Orden (wie Anm. 1), S. 131; Beuttel, Der Generalprokurator (wie Anm. 15), S. 75 f.; H. Houben, San Leonardo di Siponto e l'Ordine Teutonico in Puglia, in: San Leonardo di Siponto. Cella monastica, canonica, domus Theutonicorum (Acta Theutonica 3), hrsg. v. H. Houben, Galatina 2006, S. 91-110, hier S. 110; Houben, Die Landkomture (wie Anm. 2), S. 152.

21 So in einem Protest des Vinzenz von Leubint aus April 1474 und in anderen Aktenkopien in Geheimes Staatsarchiv Preußischer Kulturbesitz, XX. H.A., Ordensbriefarchiv, Nr. 16478.

22 Von 1433 bis 1440 hatte die Ballei jährlich zwischen 2000 und 9000 Goldflorinen Bareinkommen (La contabilità delle Case dell'Ordine Teutonico in Puglia e in Sicilia nel Quattrocento, hrsg. v. K. Toomaspoeg (Acta Theutonica 2), Galatina 2005, S. lviii), um 1473 ging seine Wirtschaft gar nicht viel schlechter.

23 Schumacher, Studien (wie Anm. 5), I, S. 223.

241474 März 19.: Ordensbriefarchiv (wie Anm. 21), Nr. 16473, Regest in: Regesta historicodiplomatica Ordinis S. Mariae Theutonicorum 1198-1525, Pars I, bearb. v. E. Joachim, hrsg. v. W. Hubatsch, vol. 2, Göttingen 1950, S. 213. 
gleichzeitig dem König seine Version der Ereignisse vorlegte. ${ }^{25}$ Im August I 47 I forderte Ferdinand I. den Hochmeister auf, Grube als Verwalter des apulischen Ordensbesitzes zu bestätigen. Da dieser vom König als sein Ratgeber bezeichnet wurde, muss er zum engerem Umkreis Ferdinands I. gehört haben. Das Hauptargument des Königs zugunsten Grubes war, dass dieser eine gute Verwaltung der Balleigüter garantieren könne, was in der Vergangenheit nicht der Fall gewesen sei. ${ }^{26}$ Der Hochmeister Heinrich Reffle von Richtenberg und der Deutschmeister Ulrich von Lentersheim haben über die Lage der Ballei Apulien diskutiert, ${ }^{27}$ und der Generalprokurator Johannes Rehwinkel hat den Hochmeister darüber informiert. ${ }^{28}$ Die doppelte Unterstützung durch König und Papst verlieh aber Grube eine unanfechtbare Position.

Andere interessante Hintergründe gehen aus einem Brief hervor, den der Statthalter des Ordens in Sizilien, Heinrich Hoemeister, im August I 476 dem Deutschmeister Ulrich von Lentersheim schrieb. ${ }^{29}$ Hoemeister, den die Ordensarchivare im I 8. Jahrhundert als fons et origo mali bezeichneten, ${ }^{30}$ ist wahrscheinlich identisch mit einem 1460 bezeugten deutschen Einwohner von Padua, ${ }^{31}$ der später in den Deutschen Orden eintrat und I 467-I 468 Statthalter und Prokurator des Landkomturs von Lamparten war. ${ }^{32}$ Der Brief Hoemeisters war die Antwort auf ein Schreiben des Deutschmeisters vom i 4. April, in dem dieser ihn beschuldigt hatte, mit Stephan Grube ein Bündnis (amicitia seu pactum) gegen Vinzenz Leubint geschlossen zu haben. ${ }^{33}$ Hoemeister schwur, dem Deutschmeister und

251474 April 26.: eine Kopie des Protestbriefs des Leubint findet sich in Ordensbriefarchiv (wie Anm. 21), Nr. 16478, f. 1r-2v (Regest in: Regesta historico-diplomatica (wie Anm. 24), Pars I, vol. 2, S. 213). Einer von seiner Argumente war, dass die Komturen des Deutschen Ordens Ritter gewesen seine sollten, während Grube ein Priester war. Eine Kopie des Schreibens von Grube an den König ist teilweise erhalten in Ordensbriefarchiv (wie Anm. 21), Nr. 16478, f. 6r.

261474 August 31.: Kopie in Ordensbriefarchiv (wie Anm. 21), Nr. 16501 (Regest in: Regesta historico-diplomatica (wie Anm. 24), Pars I, vol. 2, S. 215).

271475 August 25.: Ordensbriefarchiv (wie Anm. 21), Nr. 16565 (Regest in: Regesta historicodiplomatica (wie Anm. 24), Pars I, vol. 2, S. 220).

28 1476: Ordensbriefarchiv (wie Anm. 21), Nr. 16646 (Regest in: Regesta historico-diplomatica (wie Anm. 24), Pars I, vol. 2, S. 225).

291476 August 10., hier im Anhang.

30 Wien, Zentralarchiv des Deutschen Ordens, Abteilung Welschland, 152/1, f. 76 r.

31 1460 Februar 11.-19.: Padua, Archivio di Stato, Corporazioni religiose soppresse-Gesuiti, Bd. 155, Nr. 4.

32 Padua, Archivio di Stato, Corporazioni religiose soppresse-Gesuiti, Bd. 155, Nr. 6 und Bd. 159, Nr. 55.

33 Schon 1474 kommt die Verbindung zwischen Hoemeister und Grube vor: 1474 März 19.: Ordensbriefarchiv (wie Anm. 21), Nr. 16473 (Regest in: Regesta historico-diplomatica (wie Anm. 24), Pars I, vol. 2, S. 213). 
dem Orden immer treu geblieben zu sein, musste jedoch zugeben, Grube einige nicht näher bezeichnete Güter übertragen zu haben. Grube, jetzt Bischof von Troia, hätte mit Vinzenz Leubint in Siponto einen Vertrag geschlossen, in dem er ihm die Erstattung seiner Reisekosten versprochen habe. Grube selbst sei jetzt in Neapel und hätte die Verwaltung von Siponto einem Prokurator, dem Richter Gabriel, übertragen. Leubint sei hingegen nach Sizilien gefahren, wo er sechs Tage geblieben sei und von Hoemeister Geld erhalten habe. Der Zweck des Briefes ist es, Grube als einen Verräter, Lügner und Betrüger darzustellen und Leubint als eine habgierige und inkompetente Person. Aus dem Brief geht ferner hervor, dass einige Brüder der Ballei Apulien, die dem Deutschmeister treu geblieben waren, wie Johannes Kapfer, ${ }^{34}$ verhaftet worden waren und nach ihrer Freilassung nach Sizilien gegangen waren. Hoemeister hatte dem Deutschmeister auch andere geheime Informationen mündlich mittels eines Boten zukommen lassen sowie in der Vergangenheit Briefe über die spanischen Ordensbesitzungen, die er jetzt zurückhaben wollte. Schließlich wollte Hoemeister wichtige Veränderungen im Personal der Ballei Sizilien vornehmen. Der in einem gelehrten 'Kirchenlatein' geschriebene Brief zeigt deutlich, dass der Deutschmeister und somit der Deutsche Orden die Kontrolle über die Ballei Sizilien verloren hatte und dass der Statthalter des Ordens in Sizilien auf eigene Faust zwischen Grube und Lentersheim agierte, um seine persönliche Stellung zu festigen.

Doch nun zurück nach Apulien. Hier versuchte I 480 der Hochmeister Truchsess von Wetzhausen durch einen Vertrag mit Stephan Grube die Rechte des Ordens an der Ballei Apulien zurückzugewinnen. Grube, der ein Mitglied des Ordens geblieben war, wurde gleichzeitig Generalprokurator in Rom und Erzbischof von Riga. Doch in den Augen der römischen Kurie war die Ballei Apulien eine päpstliche Kommende und wurde nach Grubes Tod im Dezember 1483 bis ins I 8. Jahrhundert Kardinälen zugeteilt. ${ }^{35}$ Die Beschlagnahme von Kirchenbesitz in Süditalien und in ganz Europa war damals verbreitet. Der Deutsche Orden war, im Unterschied zu anderen Institutionen, nicht in der Lage, sich dem zu widersetzen.

Das Schicksal der Ordensbesitzungen in Sizilien war ähnlich, auch wenn der Orden sich hier zwanzig Jahre länger hielt. ${ }^{36}$ Der Deutschmeister verlieh zwischen

34 Dieser diente zuerst 1464 als Priesterbruder in Sizilien, demnach war in Apulien tätig. Um 1476 wurde er freigelassen und ist in Sizilien zurückgekommen: damals war er schon ein alter und kranker Mann. In den Jahren 1478 und 1480 findet man ihm noch im Balleikapitel. Siehe das Brief Hoemeisters hier im Anhang; und Palermo, Archivio di Stato, Commenda della Magione, Bd. 9, f. 1r-11r; Bd. 11, f. 239r-241r; Bd. 607, f. 30r-32v.

35 Forstreuter, Der Deutsche Orden (wie Anm. 1), S. 131.

36 Dazu Schumacher, Studien (wie Anm. 5), II, S. 9-25; Forstreuter, Der Deutsche Orden (wie Anm. 1), S. 117-118; Toomaspoeg, Les Teutoniques en Sicile (wie Anm. 14), S. 300-314; ders., Ultimi Teutonici (wie Anm. 17). 
I 484 und I 486 dem Statthalter Heinrich Hoemeister den Titel eines Landkomturs, denn er sah keine Möglichkeit, sich dieses offensichtlich unzuverlässigen Mannes zu entledigen. Hoemeister hatte sich seit I 47 I eine Machtposition aufgebaut, in der ihm alle Brüder direkt unterstellt waren und er allein die Wirtschaftsführung der Ballei, die am Ende keinen Tressler mehr hatte, bestimmte. Er verfügte auch über ein Netzwerk von hochrangigen Freunden, das bis zum aragonesischen Königshof reichte und es ihm gestattete, alle Versuche des Ordens, ihn auch nur in begrenztem Maße zu kontrollieren, abzublocken. Diese problematische Situation kam ans Licht, als ein angesehener deutscher Einwohner von Palermo, Johannes Adam, im Mai I 49 I mit Hilfe des Deutschordensbruders Nikolaus Kirsten einen Brief schrieb, in dem er Hoemeister beschuldigte, die Ballei Sizilien dem König von Aragon übergeben zu wollen. ${ }^{37}$

Was folgte, ist bekannt: Bereits im Juni I 49 I ordnete der Deutschmeister Andreas von Grumbach eine Visitation der Ballei an, die im September begann, aber nicht beendet werden konnte. ${ }^{38}$ Heinrich Hoemeister wandte sich nämlich an die päpstliche Kurie und den aragonesischen Königshof und erreichte, dass König Ferdinand 1492 die Güter der Ballei vorläufig beschlagnahmte. Die Visitatoren, Wilhelm von Wayblingen, Landkomtur von Lamparten und der inzwischen verloren gegangenen Balleien von Apulien und Griechenland, ${ }^{39}$ und der Priesterbruder Adolf von Geroldseck, ${ }^{40}$ versuchten vergeblich die Situation zu verändern: Wayblingen wurde 1492 oder I 493 der letzte Landkomtur von Sizilien und Geroldseck blieb bis zu seinem Tod auf der Insel.

37 Schumacher, Studien (wie Anm. 5), II, S. 11.

38 Visitationen im Deutschen Orden im Mittelalter, Bd. II (1450-1519), hrsg. v. M. Biskup, I. Janosz-Biskupowa, Red. U. Arnold (Quellen und Studien zur Geschichte des Deutschen Ordens 50/II, Veröffentlichungen der Internationalen historischen Kommission zur Erforschung des Deutschen Ordens 10/II), Marburg 2004, Nr. 210, S. 201-216.

39 Ritterbruder aus Württemberg, Komtur in Padua von 1475 bis 1478, dann Landkomtur in Lamparten mindestens seit Juni 1480 bis zu seinem Tod in 1497.

40 Priesterbruder, Komtur in Bologna in 1482 und in Brixenei in 1491, 15. Februar 1508 in Sizilien gestorben. Als Adolf im Jahr 1482 in einer Urkunde Gangolfs Herrn zu Hohengeroldseck vorkommt (1482 August 29.: Generallandesarchiv Karlsruhe, 111/305, ich danke Herrn Udo Arnold für diese Nachricht), handelt sich weder um ein Mitglied der Hauptlinie des Adelsgeschlechts (Hohen)geroldseck in der Ortenau (C. Bühler, Die Herrschaft Geroldseck: Studien zu ibrer Entstehung, ihrer Zusammensetzung und zur Familiengeschichte der Geroldsecker im Mittelalter (Veröffentlichungen der Kommission für geschichtliche Landeskunde in BadenWürttemberg: Reihe B, Forschungen 96), Stuttgart 1981), weder um eine seine Nebenlinie, wie dieser in Sulz am Neckar (H.-P. Müller, Die Sulzer Linie der Freiherren von Geroldseck. Neueste genealogische Forschungsergebnisse über die Adelsfamilie, Sulzer Heimat 16 (1990), S. 1-4), und nicht um eine kleinere lokale fränkische Familie. 
In dieser schwierigen Lage wandte der Orden sich an seinen offiziellen Protektor an der römischen Kurie, den Kardinal Rodrigo Borgia, der jedoch am 2. Mai 1492 von Papst Innozenz VIII. die Ballei für sich selber erhielt. ${ }^{41}$ Wenig später wurde Rodrigo Borgia zum Papst gewählt (Alexander VI.) und die Güter der Ballei Sizilien wurden dem Kardinal Friedrich von Sanseverino übergeben. Schließlich kam die Ballei am I I. März I 495 an den Erzbischof von Zaragoza Alfons von Aragon, einen Sohn Ferdinands des Katholischen. ${ }^{42}$ Der aragonesische Königshof hatte schon seit langem auf eine Gelegenheit gewartet, sich der Ballei Sizilien zu bemächtigen. Wie Antonio De la Torre gezeigt hat, gab es einen Plan zur Schaffung einer königlichen 'Kirchenreserve', die aus den Gütern verschiedener Kirchen, Klöster und Orden mit einem zu erwartenden Gesamteinkommen von 16000 Goldflorinen bestehen sollten. ${ }^{43}$ Nun wurden die Besitzungen der Ballei Sizilien zum Kern dieser in der Neuzeit als "Commenda della Magione“ bekannten 'Reserve.'44

Der aragonesische Königshof hatte die Einziehung der Güter der Ballei bereits seit langem beschlossen und es gab keine Möglichkeit, ihn davon abzubringen. Unklar bleibt dabei die Rolle des Landkomturs Hoemeister. Seine wichtigsten Ankläger I49I in Palermo, die eigentlich die folgenden Ereignis verursachten, hatten persönliche Motive, um gegen Hoemeister vorzugehen: Johannes Adam schuldete ihm Geld ${ }^{45}$ und der ehrgeizige Nikolaus Kirsten war vom Landkomtur in die abgelegene Kommende Margana verbannt worden. Der betagte Landkomtur war nur dann interessiert, sein Leben zu genießen und seine Einkünfte weiter zu beziehen. Ob er schon im September I 49 I konkrete Pläne zur Veräußerung der Ballei hatte, wissen wir nicht.

Nach dem Verlust Siziliens war allen klar geworden, dass der Deutsche Orden an der römischen Kurie nicht über genügend Einfluss verfügte, um seine Rechte auf der italienischen Halbinsel zu schützen. Dies lag aber nicht am verminderten internationalen Ansehen des Ordens, denn auch die drei Briefe, die Kaiser Maximilian I. am I r. März I 498 an König Ferdinand, den Papst Alexander VI. und das Kardinalskollegium schrieb mit der Bitte um eine Rückgabe der Balleien Apulien

41 Mongitore, Monumenta (wie Anm. 16), S. 145-147.

42 Ebd., S. 148-151.

43 A. De la Torre, Unas noticias de la Orden militar de Caballeros teutones, Gesammelte Aufsätze zur Kulturgeschichte Spaniens 13 (1958), 3, S. 270-274.

44 Siehe A. Giuffrida, Il potere del segno. La transizione della Magione da baliato a commenda, in: I Cavalieri Teutonici tra Sicilia e Mediterraneo, hrsg. v. A. Giuffrida, H. Houben, K. Toomaspoeg (Acta Theutonica 4), Galatina 2007, S. 159-202.

45 Toomaspoeg, Ultimi Teutonici (wie Anm. 17), S. 157. 
und Sizilien ${ }^{46}$ sowie spätere ähnliche Bitten deutscher Fürsten und der Stadt Palermo hatten keinen Erfolg.

Nach Kurt Forstreuter veränderte sich die Lage infolge neuer Machtverhältnisse in Europa, wie z. B. dem Ausbruch des Konflikts zwischen Venedig und Kaiser Maximilian, ${ }^{47}$ und verschlechterte sich besonders unter Papst Julius II. ( $1503-1513$ ), der dem Orden feindlich gesinnt war. ${ }^{48}$ Doch, wie Forstreuter bemerkte, verbargen sich hinter der Vertreibung des Ordens aus Italien sicherlich auch lokale Ursachen, ${ }^{49}$ die meines Erachtens den wichtigsten Grund für den Verlust der Ballei Lamparten darstellen.

Nord- und Mittelitalien befanden sich damals in einer schwierigen wirtschaftlichen und politischen Lage, die durch den fast permanenten Kriegszustand zwischen der neuen spanischen Monarchie, welche die beiden Königreiche von Sizilien beherrschte, Venedig, Florenz, Mailand und anderen italienischen Staaten, dem Imperium und dem Königreich Frankreich. Weite Teile des Landes litten unter der Anwesenheit von Söldnern, die Geld- und Lebensmittelknappheit verursachten. Die Haltung des Papsttums gegenüber den Balleien des Deutschen Ordens hing nicht allein von seinen politischen Zielen im Imperium und im Königreich Polen ab, sondern auch von der Notwendigkeit, seine Interessen in Italien, wo die Macht und der Einfluss der römischen Kirche im Vergleich zur Vergangenheit stark zurückgegangen waren, mit allen Mitteln, zu denen auch Kompromisse gehörten, zu verteidigen.

Die ersten Zeugnisse der sich verändernden Haltung der lokalen Mächte gegenüber dem Deutschen Orden kommen aus Bologna. Noch I 47 I hatte der Generalvikar des Bischofs von Bologna die Interessen der Ballei Lamparten verteidigt..$^{50}$ Jetzt, 1497 oder I 498, befahl hingegen ein anderer Generalvikar dem Prior der Ordenskirche in Bologna unter Androhung der Exkommunikation und einer Geldstrafe, ein kürzlich in der dortigen Elisabethkapelle geschaffenes Grabmal abzureißen. ${ }^{\text {SI }}$ Es gab starke Spannungen zwischen den Interessen der Ordenskirche, die damals von einem einheimischen Kaplan geleitet wurde, und denen des Bischofs von Bologna. Piotr Czierzniakowski hat bemerkt, dass der Hauskomtur von Bologna, Kaspar von Karben, am Anfang des Jahres I 506 versuchte, Mitglied

46 Wien, Zentralarchiv des Deutschen Ordens, Abteilung Welschland, 125, f. 224r-225v, 257v.

47 Forstreuter, Der Deutsche Orden (wie Anm. 1), S. 144.

48 Ebd.

49 Ebd., S. 145

50 M. Fanti, G. Roversi, S. Maria degli Alemanni in Bologna, Bologna 1969, S. 22.

51 1497-1498: Archivio Generale Arcivescovile di Bologna, Ricuperi attuariali, filza 27. 
des Domkapitels der Stadt zu werden, ${ }^{52}$ was zum zwei Jahre später erfolgten Verlust des Hauses beigetragen haben könnte. ${ }^{33}$ Die Beschlagnahme wäre also die Folge eines Konflikts zwischen Orden und Bischof gewesen.

Das Hauptproblem war aber die Tatsache, dass das zum Kirchenstaat gehörende Bologna seit 1463 unter der Herrschaft des Johannes II. von Bentivoglio stand, ${ }^{54}$ der seit Beginn des I 6. Jahrhunderts aufgrund eines Konflikts mit Cesare Borgia, dem Sohn Papst Alexanders VI., in schlechten Beziehungen zur römischen Kirche stand. 55 Die Bentivoglio betrachteten sich als Nachfolger König Enzios von Sardinien, dem Sohn Kaiser Friedrichs II., der von I 249 bis I 272 in Bologna gefangen gehalten worden war. 1494 hatte Kaiser Maximilian Johannes II. in den Status eines Pfalzgrafen erhoben, der das Recht hatte, den schwarzen Reichsadler in sein Wappen aufzunehmen. ${ }^{6}$ Dies könnte das Interesse Johannes' II. am Deutschen Orden erklären, auch wenn die genauen Ursachen der Spannungen nicht aus den Quellen hervorgehen.

Im November I 506 war Johannes II. von Bentivoglio gezwungen, Bologna zu verlassen, und die Stadt wurde von Julius II. erobert, der die militärischen Aktionen persönlich leitete. ${ }^{57}$ Nun wurden die ehemaligen Verbündeten der Bentivoglio verhaftet und bestraft. Der Verlust der Ordenskirche S. Maria degli Alemanni erfolgte aber erst nachdem der Papst Bologna verlassen hatte, zur Zeit eines vom Kardinallegaten Francesco Alidosi da Imola, Bischof von Pavia, niedergeschlagenen Aufstands in der Stadt..$^{8}$ Eine der ersten Maßnahmen des Kardinallegaten, der

52 P. Cierzniakowski, L'Ordine Teutonico nell'Italia settentrionale, in: L'Ordine Teutonico nel Mediterraneo, hrsg. v. H. Houben (Acta Theutonica 1), Galatina 2004, S. 217-235, hier S. 231; aus Protokolle der Kapitel und Gespräche des Deutschen Ordens im Reich (1499-1525), hrsg. v. M. Biskup, I. Janosz-Biskupowa (Quellen und Studien zur Geschichte des Deutschen Ordens 41, Veröffentlichungen der Internationalen Historischen Kommission zur Erforschung des Deutschen Ordens 3), Marburg 1991, Nr. 15, S. 85-86.

53 Cierzniakowski, L'Ordine Teutonico (wie Anm. 53), S. 231.

54 R. Dondarini, Bologna medievale nella storia delle città, Bologna 2000, S. 333-341; siehe auch S. Cucini, L'esprit «national» des villes communales des États Pontificaux à la fin du Moyen Age. Le cas de Bologne, Revue de l'Istitut Français d'Histoire en Allemagne 6 (2014), on-line.

55 G. Fasoli, I Bentivoglio, Florenz 1936.

56 A. De Benedictis, Lo stato popolare di libertà: pratica di governo e cultura di governo (1376|-1506), in: Storia di Bologna, Bd. II: Bologna nel Medioevo, Bologna 2007, S. 899-950, hier S. 924.

57 Siehe Le due spedizioni militari di Giulio II tratte dal diario di Paride Grassi Bolognese, hrsg. v. L. Frati, Bologna 1886; S. Muzzi, Annali di Bologna dalla sua origine al 1796, Bd. V, Bologna 1843, S. 474-521.

58 Muzzi, Annali (wie Anm. 57), S. 570. 
die Herrschaft in Bologna im Namen des Papstes ausübte, war die im Juni I 508 erfolgte Besetzung des Deutschordenshauses in Bologna. ${ }^{99}$

Es bleibt unklar, ob die Ordensbrüder zu den wichtigsten 'Freunden' Johannes' II. gehört hatten. Die Beschlagnahme ihrer Kirche deutet aber darauf hin. Zwar kam es in dieser unruhigen Zeit auch zu Übergriffen auf andere religiöse Orden, ${ }^{60}$ aber der Verlust des Ordenshauses kann wohl nur als Strafmaßnahme verstanden werden. Dies legt ein Vergleich mit dem Johanniterorden nahe, der in Bologna als Verbündeter des Papstes agierte, und in dessen Haus Julius II. im November I 506 wohnte. $^{61}$

Die Besetzung der Kirche und der Kommende des Deutschen Ordens waren wohl ursprünglich nicht als definitive Maßnahme gedacht, und der Komtur von Karben konnte sein Amt noch bis zu seinem Tod I 5 I I ausüben. Danach wurde der Ordensbesitz jedoch eine Pfründe der Kirche von Bologna. ${ }^{62}$ I 576 löschte Papst Gregor XIII. auch die letzten Spuren der Ordenszeit von S. Maria degli Alemanni aus und verwandelte das Priorat in eine Pfarrkirche. Auf diese Weise wurden die Güter der ehemaligen Ordenskommende aufgeteilt und die Präsenz des Deutschen Ordens in Bologna endgültig beendet. ${ }^{63}$

Wenig später ging auch das Ordenshaus in Venedig verloren. Die wichtigste Quelle zu diesem Verlust sind die Tagebücher des venezianischen Chronisten Marin Sanudo des Jüngeren ( $1466-1$ 5 36) ${ }^{64}$ die uns Umstände zeigen, die von denen in Bologna verschieden sind. Alles begann am I 4. April I 5 I 2, als der Komtur von Venedig, Albert von Laumersheim, ${ }^{65}$ während einer Reise von Venedig ins Friaul

59 Forstreuter, Der Deutsche Orden (wie Anm. 1), S. 152; Fanti, Roversi, S. Maria (wie Anm. 51), S. 29. Die offizielle Ursache dazu war, dass der lokale Komtur Kaspar von Carben nicht regelmäßig ins Amt genommen gewesen sei.

60 Muzzi, Annali (wie Anm. 57), S. 565-566.

61 Ebd., S. 507.

62 Siehe Forstreuter, Der Deutsche Orden (wie Anm. 1), S. 152; Fanti, Roversi, S. Maria (wie Anm. 51), S. 29.

63 Fanti, Roversi, S. Maria (wie Anm. 51), S. 36

64 Marin Sanudo, I diarii (MCCCCXCVI-MDXXXIII), hrsg. v. R. Fulin, F. Stefani, N. Barozzi, G. Berchet, M. Allegri, Venedig 1879-1902, eine Zusammenfassung in R. Predelli, Le reliquie dell'archivio dell'ordine Teutonico in Venezia, Atti del Reale Istituto Veneto di scienze, lettere ed arti 64 (1904-1905), 2, S. 1379-1463, hier S. 1384-1386.

65 Laumersheim war Komtur in Brixenei von 1493 bis 1498, dann Prokurator des Statthalters der Ballei Lamparten in 1498, danach, mindestens seit April 1506, Komtur in Venedig (siehe Wien, Zentralarchiv des Deutschen Ordens, Abteilung Handschriften, 164, S. 369; Padua, Archivio di Stato, Corporazioni religose soppresse-Gesuiti, Bd. 162, Nr. 10). Er war Mitglied einer ursprünglich aus Laumersheim im Pfalz (Landkreis Bad Dürkheim) herauskommender in der Neuzeit gut bekannter Adelsfamilie, die sich genau in diese Epoche ausdehnte. 
im Fluss Livenza ertrank. ${ }^{66}$ Einige Monate später, am 2. September I 5 I 2 , übertrug Papst Julius II. die Kommende Venedig an Andrea Lippomano. ${ }^{67}$

Die Lippomano waren ein seit dem I 0 . Jahrhundert in Venedig residierendes Geschlecht, das seit I 38 I zum Patriziat gehörte, und von dem viele Mitglieder im Maggior Consiglio, dem Stadtrat saßen. ${ }^{68}$ Doch zu Beginn des I6. Jahrhundert war diese Familie in Schwierigkeiten, da ihre Geldgeschäfte (sie besaß eine Bank) die Lippomano an den Rand des Ruins gebracht hatten. Im Mai I 504 beschäftigte sich der venezianische Senat mit der Rückzahlung des ihren Kreditoren geschuldeten Geldes ${ }^{69}$ und im Dezember 15 I 2 war wegen eines anderen gescheiterten Geldgeschäfts ein Prozess gegen den Vater und die Onkel des Andrea Lippomano im Gange. ${ }^{70}$ Wie Riccardo Predelli beobachtet hat, traten die Lippomano deswegen in den Dienst der Päpste und erhielten von diesen wichtige Pfründen. ${ }^{71}$ Zur gleichen Zeit findet man die Familie aber auch im Dienst der Republik Venedig, nicht selten als Vermittler zwischen der Lagunenstadt und der Kurie. Andrea, der sicher nicht zu den wichtigsten Mitgliedern der Familie gehörte, nahm später am Konzil von Trient teil und ist vor allem deswegen bekannt, weil er die Jesuiten unterstützte und ein Freund von Ignatius von Loyola war. Andrea starb I 574, war also i 5 I2, als er zum ersten Mal in den Quellen erscheint, noch ein sehr junger Mann, ${ }^{72}$ vielleicht noch ein Kind.

Die Aktionen der Kurie zugunsten des Andrea Lippomano beruhen auf den Beziehungen der Päpste Julius II. (I 503 - I 5 I 3 ) und Leo X. (I 5 I 3 - I 52 I) zu seinem Vater Girolamo di Tomaso Lippomano. Julius II. verlieh in der Tat die Kommende nicht Andrea, sondern seinem Vater. Dieser hatte sich, unmittelbar nachdem er die Nachricht vom Tod des Komturs Laumersheim erhalten hatte, persönlich an die Kurie begeben, um die Kommende zu erhalten. ${ }^{33} \mathrm{Er}$ ist auch als Hironimo de Banco bekannt und war I 5 I I der Vertreter Venedigs an der päpstlichen Kurie gewesen. ${ }^{74}$ Als der Deutsche Orden 15 I 4 offiziell in Rom gegen die Beschlagnahme des venezianischen Ordneshauses protestierte, rief Leo X. Girolamo zu sich. Dabei wurde er als „enger Freund” („forte amico“) des Papstes bezeichnet.75 Es

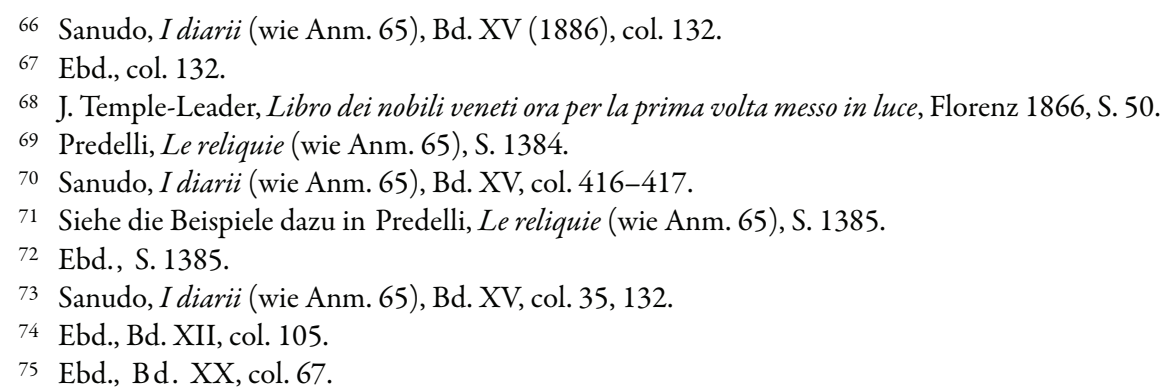


handelte sich also bei den Lippomano um eine Familie, die von den Päpsten Julius II. und Leo X. für die ihnen geleisteten Dienste belohnt wurde.

Wie in Bologna so wurde auch in Venedig das Ordenshaus von den Päpsten nicht als ein Teil der Ballei Lombardei betrachtet, sondern als eine eigene Verwaltungseinheit. In den Quellen spricht man von einem „Priorat“, das von einem Prior verwaltet wurde, ähnlich wie eine Pfründe. Im Unterschied zu Bologna war aber die Deutschordenskirche in Venedig (S. Trinità) auf einem vom Orden im I 3. Jahrhundert erhaltenen Grundstück in dieser Stadt errichtet worden und unterstand somit, zumindest in der Theorie, nicht der römischen Kirche. Daher konnte das dortige Deutschordenshaus nur mit Zustimmung der städtischen Behörden übertragen werden, was bereits am 23. Oktober 15 I 2 erfolgte, als der Senat von Venedig anordnete, den venezianischen Ordensbesitz dem Andrea Lippomano zu übergeben, was umgehend erfolgte. ${ }^{76}$

In diesem Fall handelte es sich offensichtlich nicht um eine Strafmaßnahme, sondern um eine innenpolitische Entscheidung, bei der die Familie Lippomano von der Stadt und vom Papst unterstützt wurde, der ein Bündnis mit Venedig anstrebte. Die Rechte des Deutschen Ordens wurden zurückgestellt, denn, wie Udo Arnold betont hat, hatten der Orden und Venedig nach der türkischen Eroberung Griechenlands keine gemeinsamen Interessen mehr, und der Orden wurde nun vielleicht auch als Verbündeter Kaiser Maximilians betrachtet, gegen den Venedig kurz zuvor gekämpft hatte. ${ }^{77}$ Venedig und Maximilian waren zwar I 5 I 2 offiziell wieder Verbündete, aber dies genügte wohl nicht, um die Erinnerung an den kaiserlichen Feldzug nach Padua und Treviso im Jahr I 509 auszulöschen.

Bekanntlich veränderten sich die Beziehungen zwischen Venedig und dem Papsttum am Anfang des I6. Jahrhunderts. Nachdem sich beide im Rahmen der Liga von Cambrai bekämpft hatten, annullierte der Papst am 24. Februar i 5 io das Interdikt und schloss ein Bündnis mit Venedig, das I 5 I I mit der Heiligen Liga offiziell wurde. Jetzt sollten Maximilian, Julius II. und der Doge Leonardo Loredan gemeinsam gegen Frankreich kämpfen. Dadurch wurden die Lippomano als Vermittler zwischen der römischen Kurie und der Republik Venedig begünstigt.

Im Fall Venedigs spielen aber auch die inneren Entwicklungen des dortigen Ordenshauses und seiner Verwaltung eine Rolle. Die örtliche Laienbruderschaft der Ordensfamiliaren hatte eine solche Eigenständigkeit erreicht, dass es eine gewisse Vermischung zwischen dem Orden und seiner Niederlassung in der Stadt

76 Ebd., Bd. XV, col. 255.

77 U. Arnold, Der Deutsche Orden und Venedig, in: Militia Sacra. Gli ordini militari tra Europa e Terrasanta, hrsg. v. E. Coli, M. De Marco, F. Tommasi, Perugia 1994, S. 145-165, hier S. $155-157$. 
gab. Diese Autonomie des Ordenshauses wurde durch seine Beschlagnahme offiziell. Streng juristisch betrachtet handelte es sich nicht um eine Beschlagnahme, sondern nur um die Ernennung eines neuen Priors, so wie sie etwa in Sizilien I 430 erfolgt war. Auch waren die Lippomano in einem gewissen Maße religiös dem Deutschen Orden verbunden. So hat Andrea Lippomano später auf seinen Grabstein in der ehemaligen Ordenskirche in Padua schreiben lassen: Ordinis Theutonici Eques et Prior ${ }^{78}$ und wie in der Toskana oder in Palermo wurde auch in Venedig durch das Personal des Hauses die Tradition des Ordens weitergeführt. Als Papst Paul III. im Februar I 546 die Kirche der heiligen Dreifaltigkeit an Pietro Lippomano, den knapp zehnjährigen Sohn eines Bruders des Andrea, übergab, versprach dieser, das Ordensgewand zu tragen. ${ }^{79}$ Nach Riccardo Predelli war das Geschlecht der Lippomano ursprünglich deutscher Herkunft, ${ }^{80}$ was aufgrund der Namensform theoretisch denkbar ist, auch wenn die Familie aus Negroponte (Euböa) nach Venedig gekommen war.

Der Prozess des Verlusts der Ordensbesitzungen im Herrschaftsgebiet der Republik Venedig, das das ganze heutige Veneto und einen Großteil Friauls umfasste, ging weiter, als nach Venedig im Jahr I 5 I 6 aus ganz ähnlichen Gründen auch die Kommende Brixenei (Precenicco) verloren ging. Girolamo di Tomaso hatte in Rom für seinen Sohn Andrea Lippomano nicht nur die Bestätigung des Ordenshauses in Venedig erhalten, sondern auch die neue Gewährung der Rechte über Brixenei, dessen Komtur Marx von Laumersheim ${ }^{81}$ vor kurzem gestorben war. ${ }^{82}$ Der Schenkungsbrief Leos X. vom 19. März I 516 wurde nur knapp zehn Tage später vom Senat von Venedig ausgeführt. ${ }^{8_{3}}$

Nach der protestantischen Reform in Deutschland verschlechterte sich die Lage des Deutschen Ordens weiter, als Papst Clemens VII. am r. Dezember I 526 auch seine letzte noch verbleibende Besitzung in der Ballei Lamparten der Familie Lippomano übergab. ${ }^{84}$ Diesmal handelte es sich um den ganzen Besitz in Padua und Umgebung, der bedeutend größer war als der in Venedig und Friaul. Auch hier wurde die Entscheidung nach dem Tod des Komturs bzw. des Landkomturs

78 Rainer, Zur Geschichte (wie Anm. 7), S. 367; Arnold, Der Deutsche Orden (wie Anm. 79), S. 156.

9 Predelli, Le reliquie (wie Anm. 65), S. 1389.

80 Ebd., S. 1384.

81 Marx von Laumersheim war Komtur in Brixenei von 1508 bis zu seinem Tod 27. Februar 1516 (Wien, Zentralarchiv des Deutschen Ordens, Abteilung Welschland, 124/2, f. 293r-322r.

82 Sanudo, I diarii (wie Anm. 65), Bd. XX, col. 67.

83 Quellen in Predelli, Le reliquie (wie Anm. 65), S. 1386.

84 Sanudo, I diarii (wie Anm. 65), Bd. XLIII, col. 132; Schellhass, Die Deutschordenskommende (wie Anm. 4), S. 92; Predelli, Le reliquie (wie Anm. 65), S. 1386. 
Philipp von Hohenstein, der am I I. Dezember 1525 am Flaum gestorben war, ${ }^{85}$ getroffen und die Ordensgüter wurden als Priorat bezeichnet. Diese Maßnahme stand im historischen Kontext des Beitritts des Papstes (im Mai I 526) zur gegen Karl V. gerichteten Liga von Cognac.

Doch dank der Tätigkeit des Vertreters des Deutschmeisters an der römischen Kurie und Statthalters in Lamparten, Dietrich von Hasslach, ${ }^{86}$ errang der Deutsche Orden diesmal einen kleinen diplomatischen Erfolg, als er gleichzeitig mit dem Verlust von Padua seine Besitzungen in Friaul zurückerhielt. Es handelte sich um ein unbequemes Grenzgebiet zwischen Habsburgern und Venezianern, das die Lippmano weniger interessierte als der reiche Ordensbesitz in Padua. Auch wenn dieser Kompromiss die Wiedergewinnung der Kommende Brixenei gestattete, so verlor der Orden dadurch endgültig den letzten Rest der Ballei Lamparten, auch wenn die neue Ordensverwaltung dagegen protestierte. Ab i 545 gehörte die Kommende Padua den Jesuiten und das Haus Venedig blieb bis I 590 unter dem Patronat der Familie Lippomano und ging nach dem Sturz der Familie in den Besitz der Serenissima über.

Nach dem Antritt seines Amts als Verwalter des Hochmeistertums (I 527 ) hat Walter von Cromberg, Meister des Deutschen Ordens in Deutschland, Italien und den partes transmarinas, mit den sogenannten Rekuperationsversuchen der italienischen Ordensbesitzungen begonnen. Am 21. Mai 1529 wurde der bereits erwähnte Statthalter in Lamparten, Dietrich von Hasslach, Vertreter Crombachs in allen Verhandlungen über den Rückerwerb der Balleien Lamparten, Apulien,

85 Ritterbruder Philipp von Hohenstein, Ordensmitglied mindestens seit 1485, war Komtur in Brixenei seit um Juni 1491, Statthalter der Ballei Lamparten seit 1498 und Landkomtur seit 14. Januar 1504 (in den italienischen Quellen wurde er aber seit Februar 1503 schon als Landkomtur und in den Ordensquellen bis Juni 1506 noch als Statthalter bezeichnet). Gleichzeitig wurde er 1515 auch Komtur in Würzburg und später Komtur in Regensburg und Mainz, 1506 war er auch Mitglied des Hl. Georgs Brüderschaft in Mergentheim. Wurde in der Ordenskirche Hl. Ägidius in Regensburg gestattet. Aus dem nassauischen Adelsgeschlecht Hohenstein an der Aar, Sohn Philipps von Hohenstein und Elisabeths Forstmeister von Gelnhausen. Sein Wappen ist in der Ägidiuskirche in Regensburg und in der Marienkirche in Brixenei dargestellt. Siehe Forstreuter, Der Deutsche Orden (wie Anm. 1); B. Klebes, Der Deutsche Orden in der Region Mergentheim im Mittelalter. Kommende, Stadt- und Territorialherrschaft (1219/20 - ca. 1525) (Quellen und Studien zur Geschichte des Deutschen Ordens 58), Marburg 2002, S. 626.

86 Dietrich, Sohn Dietrichs von Hasslach, ist in 1508 in Horneck als Ritterbruder im Deutschen Orden eingetreten, war Baumeister und Trapier in Mergentheim in 1513-1514, danach seit März 1524 Statthalter in Lamparten, vom Mai bis August 1525 Prokurator des Deutschmeister in Rom, seit 2. Februar 1526 Landkomtur in Lamparten. Im Mai 1529 wurde er Generalprokurator des Ordens bei der römischen Kurie. Er ist 9. November 1529 während eine Reise nach Rom in Bologna gestorben (Klebes (wie Anm. 87), S. 563, 718, 720). Aus einem ursprünglich aus Hasslach in Oberfranken stammendem Geschlecht. 
Sizilien und Kastilien, ${ }^{87}$ und im August desselben Jahres wurde er von Clemens VII. auch als Verwalter des Ordensbesitzes in Rom eingesetzt. ${ }^{88}$ Hasslach verhandelte mit Karl V. und schrieb ein Memorandum über die italienischen Balleien, ${ }^{89}$ starb aber schon im November 1529 in Bologna.

Das Projekt einer Rekuperation des italienischen Ordensbesitzes blieb aber lebendig, und bis zum Ersten Weltkrieg haben die Hochmeister immer wieder versucht, ihre Rechte auf die italienischen Balleien wahrzunehmen. Darüber hat sich im Deutschordenszentralarchiv in Wien eine reiche Dokumentation erhalten, die weitere wissenschaftliche Studien ermöglicht, mit denen, so ist zu hoffen, der vorliegende Beitrag in Zukunft von Spezialisten der Neuzeit weiter geführt werden kann.

Abschließend können wir feststellen, dass der Verlust der Besitzungen des Deutschen Ordens in Italien in einer Zeit stattfand, in der der Orden die letzte Phase seiner Geschichte vor der Neuordnung im Jahre I 526 erlebte. Damals befand sich Italien in einer ausgesprochen unstabilen und komplizierten politischen Situation, in der fast jeder mit jedem kriegerische Auseinandersetzungen hatte. Damals waren die Besitzrechte des Deutschen Ordens und anderer transnationaler Orden wie der Johanniter oder der griechisch-orthodoxen Gemeinschaften unklar. Der Papst hatte als oberste Instanz das Recht, sich hier einzumischen, während die Deutschordensbrüder in den aragonesischen Staaten und insbesondere in Sizilien unter dem Patronat des Königshofs standen und manchmal auch Vasallen des Königs waren. Das Hauptproblem war das Konzept der Kommende, die kirchenrechtlich betrachtet eine Pfründe war, deren Einkünfte geistlichen oder weltliche Personen übertragen werden konnten..$^{\circ}$ Es fällt auf, dass die päpstliche Kurie einzelne Balleien oder Ordenshäuser erst dann beschlagnahmte, wenn ihre Leiter gestorben oder ihres Amts enthoben worden waren, und sich in einigen Fällen ein persönliches Verhältnis zwischen Komtur, päpstlicher Kurie oder anderen weltlichen Mächten bildete. Schließlich geht aus den Quellen die entscheidende Rolle einzelner Persönlichkeiten wie die des Stefan Grube, des Heinrich Hoemei-

87 Protokolle der Kapitel (wie Anm. 52), S. 119.

881529 August 23.: Wien, Zentralarchiv des Deutschen Ordens, Urkunden.

89 Wien, Zentralarchiv des Deutschen Ordens, Abteilung Welschland, 125/1, f. 218r-219r: Militia S. Mariae Hospitalis Hierosolimitani, et ordinis Teuthonicorum nonnullas Ballivias, sive provincias habuit per Italiam diversis locis existentes, unam scilicet in Sicilia, alteram in Neapoli, tertiam autem in Longobardiâ [...].

$90 \mathrm{Zu}$ dieser Thematik siehe z. B. C. Fleury, Institutions du droit ecclésiastique, Paris 1688, S. 422-425; L. Thomassin, Vetus et nova Ecclesiae disciplina, Bd. II, Lucca 1728, S. 569-609; Fr. M. Permaneder, Commenda, in: Wetzer und Welte's Kirchenlexikon oder Encyklopädie der katholischen Theologie und ihrer Hilfswissenschaften, Bd. III, Freiburg/Breisgau ${ }^{2} 1894$, S. 693-695 . 
ster oder der Mitglieder der Familie Lippomano hervor. Es handelte sich um sehr gebildete Männer, die als geschickte Diplomaten und Politiker der Renaissancen agierten. Dabei konnten sie sich auf die Geldressourcen stützen, welche die Ordensbesitzungen abwarfen. Seit den I 640er Jahren hatte die Verwaltung des Deutschmeisters praktisch so gut wie keinen Zugriff auf diese Ressourcen mehr, die meist vor Ort blieben und so von Hoemeister und Grube benutzt werden konnten, um sich die Gunst einflussreicher Freunde zu sichern. Daraus kann man schließen, dass der Verlust der italienischen Besitzungen des Deutschen Ordens nicht eine Folge der Reformation in Kirche und Deutschen Orden war, sondern ein Zeugnis dafür, dass hier Reformen dringend notwendig waren. 


\section{ANHANG}

Palermo, 1476 August Io.

Heinrich Hoemeister, Statthalter der Deutschordensballei Sizilien, schreibt dem Deutschmeister Ulrich von Lentersheim und weist die Anschuldigungen zurück, die dieser in einem Brief wegen seiner Beziehungen zu Stefan Grube, Statthalter der Ballei Apulien, gegen ibn erhoben hatte. Er beschreibt die Lage der beiden süditalienischen Balleien und den Konflikt zwischen Grube und Vinzenz Leubint, dem neuen Landkomtur von Apulien, teilt dem Deutschmeister mit, dass er ihm durch seinen Gesandten weitere mündliche geheime Informationen übermittelt habe, bittet um die Rückgabe der Briefe über den Ordensbesitz auf der iberischen Halbinsel und schlägt personelle Veränderungen in der Ballei Sizilien vor.

Original (A), Wien, Zentralarchiv des Deutschen Ordens, Abteilung Welschland, 126/1, fol. 421r-v. Papier, $400 \times 300 \mathrm{~mm}$, ursprünglich der Länge nach sechsmal und der Breite nach viermal gefaltet; jetzt zweimal gefaltet und in Handschrift eingebunden. Dadurch und durch Feuchtigkeit leicht beschädigt. Reste eines hellroten Wachssiegels. 56 mit brauner Tinte geschriebene Zeilen.

Abschrift des 18. Jh. (B), Wien DOZA, WEL, 126/1, fol. 11r-13r.

Reverendissime gratioseque magister et domine. Quam plurimas recommendationes ab humili oratore vestro premissas et ceteras plures vestre dominationi litteras temporibus elapsis destituisse certiorem facio, super contentis tamen minime responsa aliqua percepi, dubito ne in passu itineris dimergentur, aut per pravos inique suffocentur, hac de causa modo determinatum porrigo nunctium qui litteris et verbis singula insinuare negotia oneratur. Vicinis diebus videlicet in sancti Ioannis Baptiste natalicia ${ }^{1}$ a vestra dominatione litteras ex Horneck die Pasce ${ }^{2}$ instantis anni mihi transmissas perquisivi, quas perlectas eandem dominationem vestram maxima indignatione erga me nulla tamen debita occasione mediante turbatam intellexi, cum suspicitur amiciciam aliquam seu pactum cum domino Steffano ${ }^{a}$ Gruben contraxisse, cuius causa vestre dominationi ac sacro ordini renitens fore, nec in causa domini Vincencii Leubnit Lombardie commandatarii plenominus prefuisse presumitur, ut per litterarum intersigna alter alteri destitutarum fidem huiusmodi causarum opinatur, sicuti dictis vestre dominationis litteris plurima per verba lacius continetur. Respondeo, vestra dominatio fiduciam in me habeat ratam

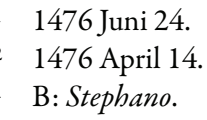


et in iota una non sit didima, semel iuravi sanctum Israel ${ }^{3}$ dominationi vestre ac sacre ordinis nostri religioni quod iuramentum pocius mori, quam in minimo transgredere scincere ${ }^{a}$ destitui. Bene est verum, unam cum certa confectionis quantitate exigui valoris ipso domino Steffano misi litteram quia in discessione a provincia Apulie eas a me exegit, unde pro re minima caristiosum me indicare honoris causa minime valui, nec obstat ubi dicitur, non libens nec rite in causa domini Vincentii prefecisse, ${ }^{\text {b }}$ certe ipse sui culpa, cum provisionem a vestra dominatione mihi statutam Neapolim penes se retinuit et me inscio contra voluntatem dominationis vestre enuclium ac conventionem traxit cuius vigore antequam adiissem civitatem Neapoli, idem dominus Steffanus episcopatum Troyanum a Romano pontifice obtinuit. Postea voto et mandato ipsius domini Vincentii Sanctum Leonardum adiens pro extrema concordia obtinenda, videlicet ipse dominus Steffanus solvere deberet singulas expensas per eundem dominum Vincentium ibidem factas, saltim ut ad patriam pacifice ex quo per hospitem pro sumptibus sequestratus fuit reddiret et sic stante conventione per me facta dominus Steffanus per manus sui scindici ${ }^{c}$ judicis Gabrielis tot aureos tradere promisit, quod singulas in hospicio per eum factas et in itinere reversionis fiendas solveret expensas. Si eum, quod ignoro, me abeunte seduxit, parum mirum, cum talis est seductor ac prevaricator, ut etiam mandatis vestre dominationis minime obedit, ne arguit responsalis littera ipsius domini Steffani, quia nullam penitus erga dominationem vestram seu votum ordinis conventionem, aut pactum dictat, vestra tamen dominatio caute laudabileque in copiarum missione egit, alias ex quo originalem nec similem unquam obtinui, minime ad hec respondere nequissem, actu cuius singularem vestre dominationi refero gratiam, et quia dicitur, mulam sibi mutuare debere, noxium non est mihi, cum ait, pro sui pecunia, nec in hoc amicicia aliqua tractatur, cum minimus ${ }^{\mathrm{d}} \mathrm{de}$ casa modicum hoc servicium prestare leviter potuisset, propterea vestra dominatio nullam penitus de me habeat opinionem contrariam, non ut arundinem, ymmo tanquam aurum fornace probatum ${ }^{4}$ vestra dominatio me fidum et erectum in omnibus habeat, siquis enim rebelle erga dominationem vestram aliquid attemptare presumpsisset, die noctuque tanquam indubitatum pugilem, non etiam requisito spiritu et animo insistere propono interim quod mihi vita comes est, a tali proposito non discedam. Et nisi pro excarceracione dominorum Ioannis Caffer

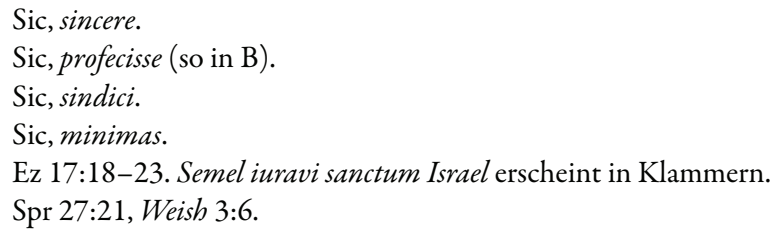


et Henrici Brulin[.. $]^{a}$ et conventione litigantium tractanda, videlicet domini Vincentii et dominationis vestre adversarii, minime dominum Steffanum in partibus Apulie, quia sibi corde et ore inimicor, visitassem, omnibus sic stantibus breviter concludo. Vestra dominatio non sit levis ad credendum unicuique, maxime linguis dolosis, contraria et minime vera informantes Altissimo placeret, ore proprio hec coram vestra dominatione redarquere valuisse, dicerem bene cuius culpa dominus Steffanus regnat, veritas tamen occultari non potest, quamdiu tegitur, ultimo preferatur, ipse qui cuncta devastavit, alios non se ipsum fosse mergi vellet, similatur lotioni manuum Pilati, ${ }^{5}$ dicitur enim de beneficiis lapidamus te, ${ }^{6}$ quam $^{\mathrm{b}}$ dominum Vincentium tandem penes me moraturum vestre dominationis honore, uti ipsa dominatio adfuisset, honorifice, digneque cum quinque equitibus per sex ebdomadas tractavi, et quindecim aureos venetos sibique mutuavi, ultra quos alios viginti duos florenos apud Messanam de nostris cepit redditibus, quos pro mei parte exigere et habere ab eodem persumme flagito, item idem promisit singulas expensas per me Neapolim factas quietari facere super redditus vestre dominationis cammere, singula tamen ad dispositionem ac voluntatem dominationis vestre remitto, si idem dominus Vincencius mihi inimicatur, Deo insinuo parum est mihi quia offensionem aliquam veracem indicare non queat, et gaudeo, quatenus defectus non est meus, vestra tamen dominatio mihi sit benivola ${ }^{c}$ et equa in omni iudicio et mandato. Presentium lator frater Nicolaus vestre dominationi notus, que non sunt scripta in hac pagina, hora a vestra dominatione ei dedita singula in singulis quia instructus distinctius aperiet quem etiam quia ydoneus ac utilis nostre religioni esset, in fratrem nostri ordinis admittere apostolica dispensatione mediante vestris litteris mandantes singulariter imploro, etiam placeat eidem dominationi vestre, siquem honestum, ordini nostro utilem et honoratum hic reperirem, eundem vestre dominationis licencia ac auctoritate mediante recolligere valeam, ne estimat vestra dominatio vilem aut inutilem, cum ordo noster his in partibus maxime ponderis et reputacionis sit, in contemptum recipere velim, unum super omnia a vestra dominatio obtinere queso, videlicet hunc sepius promissum dominum Iohannem Meler in coadiutorem aut thesaurarium mittere non dedignetis, quia solus aratrum pello, etatem habeo et erga plurima turbatus unus in omnibus locis versari non prevalet, necesse est, ut aliquis continue Panormi adsit, qui responsa alienigenis prebet. Insuper supplico, dominum Joannem Backenheym una cum vestre dominationis provisione $\mathrm{ab}$ hac patria sua enorma conversatione causante in regionem seu pro-

a Der Name ist abgekürzt.

Sic, quum.

Sic, benevola.

Matth 27:24.

Gar Ioh 10:33, De bono opere non lapidamus te sed de blasphemia. 
vinciam aliam ordinare dignemini pro quo unum aut plures morieratos ${ }^{\mathrm{a}}$ ac sobrios dominos, si placet, mandare curetis. Reverendissime magister et domine, hac vice pro censu cammere dominationis vestre ducatos transmitto centum venetos cum uno jacinto, qui contra pestem preest, ${ }^{\mathbf{b}}$ quem mei amore geratis. Item sique penes vestram dominationem sunt scripture pro commanda in Hispania servientes, destituentur, si placet, quia forsan suo tempore valebunt et prosint. Quia etiam dominus Ioannes Caffer hic penes me et tandem ductus ex Apulia, nulla vestre dominationis habita littera ne disposicione aliqua, dubitat de alia mutatione per dominationem vestram forte fienda, supplico eidem, quia senex infirmus et defectuosus est, hic residendi causa litteram cum vestre dominationis benedictione mandare dignaretis. Ut Altissimus vestram dominationem prospere conservet, et longeve vestra dominatio mihi iubeat, cuius iussu semper per me famulatur, omnique tempore obediatur. Ex Panormo, decimo augusti die sancti Laurentii nona indictione anno Domini millesimo quadringentesimo septuagesimo sexto.

Eiusdem dominations vestre humilis et obediens frater Heynricus Homeister balivie Sicilie ordinis Theutonicorum locumtenens

\section{Rückseite:}

Reverendissimo domino domino Ulrico de Lentersheym Almanie atque ordinis Theutonicorum magistro generali, suo domino gratioso.

\section{QUELLEN UND LITERATURVERZEICHNIS}

Biskup, Marian., Janosz-Biskupowa, Irena., edit. "Protokolle der Kapitel und Gespräche des Deutschen Ordens im Reich (I 499-I 525)." Marburg: Enwelt, I 99 I.

Biskup, Marian., Janosz Biskupowa, Irena., edit., Arnold, Udo., Red. "Visitationen im Deutschen Orden im Mittelalter." P. II (I450-I SIg). Marburg: Elwert, 2004.

Fleury, Claude. "Institutions du droit ecclésiastique." Paris: Hérissant, 1688.

Frati, Luigi., edit. "Le due spedizioni militari di Giulio II tratte dal diario di Paride Grassi Bolognese." Bologna: Regia, 1886.

Joachim, Erich., Hubatsch, Walter., edit. "Regesta historico-diplomatica Ordinis S. Mariae Theutonicorum I 198-I 5 I 5." Pars I., vol. 2, Göttingen: Vandenhoeck \& Ruprecht, I950.

a Sic, morigeratos.

b Sic, prodest? 
Mazzoleni, Jole., edit. "Il "Codice Chigi". Un registro della cancelleria di Alfonso I d'Aragona re di Napoli per gli anni I 45 I-I 453." Neapel: L'Arte tipografica, I 965.

Mongitore, Antonino., edit. "Monumenta historica sacrae domus mansionis SS. Trinitatis militaris ordinis Theutonicorum urbis Panormi et magni ejus praeceptoris." Palermo: ex officina typographica Joannis Baptistae Aiccardo, I 72 I.

Nobile, Francesco., edit. "I Codici di Giovan Luca Barberi sullo stato delle regalie della monarchia Siciliana nei primordi del decimosesto secolo, studio biografico-critico." Palermo: Clausen, i 892.

Sanudo, Marin. "I diarii (MCCCCXCVI-MDXXXIII)." edited by Rinaldo Fulin, Federico Stefani, Nicolò Barozzi, Guglielmo Berchet and Marco Allegri, Venedig: Visentini, I 879-1 902.

Arnold, Udo. "Der Deutsche Orden und Venedig." In Militia Sacra. Gli ordini militari tra Europa e Terrasanta, edited by Enzo Coli, Maria De Marco and Francesco Tommasi, I 45-165. Perugia: Società Editrice S.Bevignate, 1994.

Ayala Martínez, Carlos de. "Las Órdenes militares y los procesos de afirmación monárquica en Castilla y Portugal (1250-1350)." Revista da Faculdade de Letras-Historia I5 (1998), 2: I 279-I 3 I 2.

Beuttel, Jan-Erik. Der Generalprokurator des Deutschen Ordens an der römische Kurie. Amt, Funktionen, personelles Umfeld und Finanzierung. Marburg: Elwert, 1999.

Bühler, Christoph. Die Herrschaft Geroldseck: Studien zu ihrer Entstehung, ihrer Zusammensetzung und zur Familiengeschichte der Geroldsecker im Mittelalter. Stuttgart: Kohlhammer, 198 I.

Camobreco, Fortunato. Regesto di S. Leonardo di Siponto. Rom: Loescher, I 9 I 3.

Cierzniakowski, Piotr. "L'Ordine Teutonico nell'Italia settentrionale." In L'Ordine Teutonico nel Mediterraneo, edited by Hubert Houben, 21 7-235. Galatina: Congedo, 2004.

Cucini, Sara. "L'esprit «national» des villes communales des États Pontificaux à la fin du Moyen Âge. Le cas de Bologne." Revue de l'Istitut Français d'Histoire en Allemagne 6 (2014): I-6.

Dalena, Pietro. Dagli Itinera ai percorsi. Viaggiare nel Mezzogiorno medievale. Bari: Adda, 2003.

De Benedictis, Angela. "Lo stato popolare di libertà: pratica di governo e cultura di governo (1376-1 506)." In Storia di Bologna. Vol. 2, 899-950. Bologna: Bononia University Press, 2007.

Dondarini, Rolando. Bologna medievale nella storia delle città. Bologna: Pàtron, 2000.

Fanti, Mario., Roversi, Giancarlo. S. Maria degli Alemanni in Bologna. Bologna: L. Parma, 1969.

Fasoli, Gina. I Bentivoglio. Florenz: Nemi, 1936.

Fodale, Salvatore. Alunni della perdizione. Chiesa e potere in Sicilia durante il grande scisma (1372-I4I6). Rom: Istituto storico italiano per il Medio Evo, 2008. 
Fodale, Salvatore. "Antonio Olzina: un cavaliere di Santiago precettore dei teutonici nella Sicilia alfonsina." In Territorio, culture e poteri nel Medioevo e oltre. Scritti in onore di Benedetto Vetere, edited by Carmella Massaro and Luciana Petracca. Vol. I, 277-282. Galatina: Congedo, 20 I I.

Forstreuter, Kurt. "Cuba, Dietrich von." Neue Deutsche Biographie 3 ( I 957): 435.

Forstreuter, Kurt. Der Deutsche Orden am Mittelmeer. Bonn: Wissenschaftliches Archiv. 1967.

Freytag, Herman. "Die Geschäftsträger des Deutschen Ordens an der Römischen Kurie von 1309 bis I 525 ." Zeitschrift des Westpreußischen Geschichtsvereins 49 ( 1907 ): I $85-$ -220 .

Giuffrida, Antonino. "Il potere del segno. La transizione della Magione da baliato a commenda." In I Cavalieri Teutonici tra Sicilia e Mediterraneo, edited by A. Giuffrida, Hubert Houben and Kristjan Toomaspoeg, I 59-202. Galatina: Congedo, 2007.

Houben, Hubert. "Die Landkomture der Deutschordensballei Apulien (1225-1474)." Sacra Militia. Rivista di storia degli ordini militari 2 (200 I): I I 6- I 54.

Houben, Hubert. “San Leonardo di Siponto e l'Ordine Teutonico in Puglia.” In San Leonardo di Siponto. Cella monastica, canonica, domus Theutonicorum, edited by Hubert Houben, 9 I - I I o. Galatina: Congedo, 2006.

Houben, Hubert., Toomaspoeg, Kristjan., edit. Der Deutsche Orden zwischen Mittelmeerraum und Baltikum. Begegnungen und Konfrontationen zwischen Religionen, Völkern und Kulturen. Galatina: Congedo, 2008.

Josserand, Philippe. Église et pouvoir dans la Péninsule Ibérique. Les ordres militaires dans le royaume de Castille (1252-1369). Madrid: Casa de Velázquez, 2004.

Klebes, Bernhard. Der Deutsche Orden in der Region Mergentheim im Mittelalter. Kommende, Stadt-und Territorialherrschaft (I2Ig/20 - ca. I525). Marburg: Elwert 2002.

Müller, Hans-Peter. "Die Sulzer Linie der Freiherren von Geroldseck. Neueste genealogische Forschungsergebnisse über die Adelsfamilie." Sulzer Heimat I 6 ( I 990): I -4.

Muzzi, Salvatore. Annali di Bologna dalla sua origine al 1796 . Vol. 5. Bologna: Tipi di S. Tommaso d'Aquino, i 843.

Noflatscher, Heinz., edit. Der Deutsche Orden in Tirol. Die Ballei an der Etsch und im Gebirge. Marburg: Elwert, I99 I.

Permaneder, Franz M. “Commenda." In Wetzer und Welte's Kirchenlexikon oder Encyklopädie der katholischen Theologie und ihrer Hilfswissenschaften, edited by Heinrich Wetzer. Vol. 3. Freiburg im Breisgau: Herder, I 894.

Predelli, Riccardo. "Le reliquie dell'archivio dell'ordine Teutonico in Venezia." Atti del Reale Istituto Veneto di scienze, lettere ed arti 64 (I 904-I 905), 2: I 379-I 463.

Rainer, Johann. „Zur Geschichte des DO priorates SS. Trinità in Venedig vornemlich im I6. Jahrhundert." In Acht Jabrhunderte Deutscher Orden in Einzeldarstellungen, edited by Klemens Wieser, 357-370. Bad Godesberg: Wissenschaftliches Archiv, 1967.

Schellhass, Karl. "Die Deutschordenskommende zu Padua und die Jesuiten. Ein Beitrag zur Geschichte des Deutschordens in den Jahren I 5 I I I 575 ." Quellen und Forschungen aus italienischen Archiven und Bibliotheken 7 ( I 904): 9 I - I 20. 
Schumacher, Bruno. "Studien zur Geschichte der Deutschordensballeien Apulien und Sizilien." Altpreußische Forschungen I 8 (194I): I 87-230; 19 (1942): I-25.

Temple-Leader, John. Libro dei nobili veneti ora per la prima volta messo in luce. Florenz: Berbèra, I 866.

Thomassin, Louis. Vetus et nova Ecclesiae disciplina. Lucca: Venturini, 1728.

Toomaspoeg, Kristjan. "Die Brüder des Deutschen Ordens in Italien." Ordines Militares Colloquia Torunensia Historica. Yearbook for the Study of the Military Orders I9 (2014): 87-II3.

Toomaspoeg, Kristjan. "“'Confratres, procuratores, negociorum gestores et factores eorum..." Storia dei familiares dei Cavalieri Teutonici in Sicilia (I 197-I 492)." Sacra Militia. Rivista di storia degli ordini militari I (2000): I 5 I - 165.

Toomaspoeg, Kristjan., edit. La contabilità delle Case dell'Ordine Teutonico in Puglia e in Sicilia nel 2 uattrocento. Galatina: Congedo, 2005.

Toomaspoeg, Kristjan. Templari e Ospitalieri nella Sicilia Medievale. Bari: Centro Studi Melitensi, 2003.

Toomaspoeg, Kristjan. "The Teutonic Order in Italy: An Example of the Diplomatic Ability of the Military Orders." In The Military Orders, edited by Peter W. Edbury. Vol. 5 , 273-282. Burlington, Farnham: Ashgate, $20 \mathrm{I} 2$.

Toomaspoeg, Kristjan. Les Teutoniques en Sicile (1197-I492). Rom 2003.

Toomaspoeg, Kristjan. "Ultimi Teutonici di Sicilia (149 I-1 492)." Sacra Militia. Rivista di storia degli ordini militari 2 (200 I): I 55- 177.

Torre, Antonio de la. "Unas noticias de la Orden militar de Caballeros teutones." Gesammelte Aufsätze zur Kulturgeschichte Spaniens I 3 (1958), 3: 270-274.

Vincke, Johannes. "Nachrichten über den Deutschen Orden in Spanien." Gesammelte Aufsätze zur Kulturgeschichte Spaniens I 3 (1958), 3: 263-270.

\section{ABstract \\ Loss of Possessions of the Teutonic Order in Italy (End of the $15^{\text {th }}$ - Beginning of the $16^{\text {th }}$ Century)}

Between 1466 and 1526, the Teutonic Order was dispossessed of most of its properties in Italy. Those, created mostly during the 13th century, consisted in lands and buildings in more than hundred localities and produced relevant monetary incomes, so that their loss can be considered as an important economic and political defeat of the Order. My paper examines the issue, tracing the modalities and reasons of this loss, focalizing on three points: 1) the internal difficulties and intrigues of the Teutonic Order, specially the opposition between the Order's Great Master and the Master of Germany; 2) the intrigues at the papal court, considering the possessions of the big transnational congregations as ecclesiastical benefices and willing to use them to support it's foreign politics, like its relations to Aragonese Crown and to the Republic of Venice; 3) last but not least, the role 


\section{KRISTJAN TOOMASPOEG}

of individuals, like the futur bishop of Riga Stefan Grube, the commander of the Sicilian province Heinrich Hoemeister or the members of the Venetian Lippomano family, who managed through intrigues to take the control of the Order's possessions and contributed to their expropriation. A general political and religious context will also be observed, with as conclusion the affirmation that the loss of the possessions of the Teutonic Order in Italy was not caused by a reform of the Church or of the Teutonic Order but by the absence of such a reform. 